\title{
Clinical response and tolerability to abatacept in patients with rheumatoid arthritis previously treated with infliximab or abatacept: open-label extension of the ATTEST Study
}

\author{
Michael Schiff, ${ }^{1}$ Mauro Keiserman, ${ }^{2}$ Christine Codding, ${ }^{3}$ Suthin Songcharoen, ${ }^{4}$ \\ Alberto Berman, ${ }^{5}$ Sauithree Nayiager, ${ }^{6}$ Cristina Saldate, ${ }^{7}$ Richard Aranda, ${ }^{8}$ \\ Jean-Claude Becker, ${ }^{8}$ Marleen Nys, ${ }^{9}$ Manuela le Bars, ${ }^{10}$ Diane Moniz Reed, ${ }^{8}$ \\ Coralie Poncet, ${ }^{11}$ Maxime Dougados ${ }^{12}$
}

\begin{abstract}
- Additional supplementary data are published online only. To view these files please visit the journal online (http://ard. bmj.com)
\end{abstract}

${ }^{1}$ Department of Rheumatology, University of Colorado School of Medicine, Denver, Colorado, USA

2Pontificial Catholic University, School of Medicine, Porto Alegre, Brazil

${ }^{3}$ Health Research of Oklahoma, Oklahoma City, Oklahoma, USA ${ }^{4}$ Arthritis and Osteoporosis Center, Flowood, Mississippi, USA

${ }^{5}$ Centro Medico Privado de Reumatologia, Tucuman, Argentina

${ }^{6}$ St Augustine's Hospital, Durban, South Africa

${ }^{7}$ Centro de Investigacion del Noroeste, Tijuana, Mexico

${ }^{8}$ Bristol-Myers Squibb,

Princeton, New Jersey, USA

(at time of study)

${ }^{9}$ Bristol-Myers Squibb, Braine

L'Alleud, Belgium

${ }^{10}$ Bristol-Myers Squibb, RueilMalmaison, France

${ }^{11}$ Docs International, Issy les Moulineaux, France

12Paris-Descartes University, Medicine Faculty, Cochin Hospital, Paris, France

\section{Correspondence to}

Michael Schiff, Department of Rheumatology, University of Colorado, 5400 South Monaco Street, Greenwood Village, CO 80111, USA;

Imschiff@aol.com

Accepted 24 June 2011 Published Online First 12 September 2011

\section{ABSTRACT}

Objective To assess the efficacy and safety of abatacept in biological-naive patients with rheumatoid arthritis and an inadequate response to methotrexate treated in the long-term extension (LTE) of the ATTEST trial.

Methods Patients randomly assigned to abatacept, placebo or infliximab completing the 1-year double-blind period were eligible to receive abatacept $\sim 10 \mathrm{mg} / \mathrm{kg}$ in the open-label LTE. Efficacy to year 2 is presented for patients randomly assigned to abatacept or infliximab who switched to open-label abatacept. Safety data are presented for all patients entering LTE regardless of double-blind treatment.

Results Of 431 patients randomly assigned, 79.8\% remained on abatacept at year 2. At years 1 and 2, $19.7 \%$ and $26.1 \%$ of abatacept and $13.3 \%$ and $28.6 \%$ of infliximab-to-abatacept patients achieved disease activity score 28-defined remission $(<2.6)$. Safety with abatacept during the cumulative study period was consistent with the double-blind experience, with no increase in adverse event incidence following the switch to abatacept.

Conclusion In methotrexate-inadequate responders, abatacept efficacy was maintained over 2 years. For infliximab-to-abatacept patients, efficacy improvements were seen in year 2 after patients switched to abatacept. Switching directly from infliximab to abatacept was well tolerated. These data demonstrate that abatacept provides sustained responses and consistent safety, suggesting that switching from infliximab to abatacept is a viable treatment option.

Randomised clinical trials have assessed the efficacy and safety of switching to abatacept (T-cell costimulation modulator), rituximab (B-cell depleting therapy) or tocilizumab (interleukin-6 inhibitor) after failure of anti-tumour necrosis factor (TNF) agents. ${ }^{1-5}$ However, there is a paucity of information on the efficacy and safety of switching from one mechanism of action to another in patients who have not failed previous anti-TNF therapy due to lack of efficacy.

The Abatacept or infliximab versus placebo, a Trial for Tolerability, Efficacy and Safety in Treating rheumatoid arthritis (ATTEST) trial provided a unique opportunity to assess clinical efficacy and safety outcomes in biological-naive patients who switched from an anti-TNF to abatacept, regardless of earlier treatment response - that is including both patients in high, moderate or low disease states, or with American College of Rheumatology (ACR) 20, 50 or 70 responses, at the end of 12 months of infliximab treatment. Such observations could help inform clinical decision-making following treatment withdrawal for either safety or efficacy-related reasons. In the 1-year double-blind period of ATTEST, although a greater proportion of patients achieved ACR20 at month 1 with infliximab versus abatacept, by month 3 responses were similar. Both biological agents demonstrated comparable efficacy compared with placebo at 6 months; further improvements were observed with abatacept over 1 year. ${ }^{6}$ There were numerically fewer serious adverse events (SAE) and serious infections with abatacept versus infliximab over 1 year.

Here, we report the efficacy and safety from the 1-year open-label long-term extension (LTE) of ATTEST, in which all patients received open-label abatacept, regardless of double-blind treatment or treatment response.

\section{METHODS}

\section{Patients and study design}

Patients had an inadequate response to methotrexate with active disease at randomisation, as previously described. ${ }^{6}$ Patients were randomly assigned (3:3:2), using a double-dummy regimen, ${ }^{6}$ to receive intravenous abatacept $(\sim 10 \mathrm{mg} / \mathrm{kg}$ based on weight range), infliximab (fixed-dose $3 \mathrm{mg} / \mathrm{kg}$ ) or placebo, plus background methotrexate. Placebotreated patients were switched to abatacept at month 6. At month 12, patients from each treatment group could enter the open-label LTE, during which they received abatacept every 28 days. For patients switching from infliximab, there was no washout period before the first abatacept infusion. Patients were monitored monthly, at each study visit. During the open-label LTE, physicians could add a non-biological disease-modifying antirheumatic drug and adjust corticosteroid and methotrexate doses. The active-controlled ATTEST trial, requested by the authorities, was initially powered to detect reductions in disease activity with abatacept versus placebo over 6 months. Although not powered for, comparisons in safety and efficacy 
between abatacept and infliximab were prespecified. The primary objective of the open-label LTE, however, was to evaluate safety in patients who remained on treatment.

\section{Efficacy assessments}

Clinical efficacy was a secondary objective of this study, and results are presented at 6-month intervals during the open-label LTE for patients originally randomly assigned to either abatacept or infliximab, who received at least one abatacept infusion in the LTE; data for patients randomly assigned to placebo are not shown. Disease activity was assessed by the disease activity score in 28 joints (DAS28; erythrocyte sedimentation rate (ESR), low disease activity state (LDAS) $\leq 3.2$; remission $<2.6),{ }^{7}$ and by the simplified disease activity index (SDAI; low disease activity $\leq 11.0$; remission $\leq 3.3$ ). $\mathrm{ACR}^{8}$ and EULAR responses ${ }^{9}$ and health assessment questionnaire-disability index (HAQ-DI) ${ }^{10}$ scores were recorded, and are provided in the supplementary information available online only. Results are shown for patients with data available at the visit of interest (as-observed analysis).

Patient-level, post-hoc analyses of shifts in ACR responses and DAS28 status from year 1 to year 2 were performed in patients who originally received infliximab and then switched to abatacept. Mutually exclusive categories were used to define ACR responses and DAS28 status, detailed in table 1.

\section{Safety assessments}

Adverse events were monitored monthly at each study visit. The safety of abatacept during the cumulative period (1-year doubleblind plus 1-year LTE) is presented as incidence rates (IR) for patients who received at least one infusion of abatacept, regardless of initial randomisation. In addition, events that occurred during open-label abatacept treatment in patients originally randomly assigned to infliximab are shown alongside events that occurred in the double-blind period with abatacept or infliximab for comparison.

\section{RESULTS \\ Patient disposition, baseline demographics and clinical characteristics}

Of the 431 patients originally randomly assigned to abatacept $(n=156)$, infliximab $(n=165)$ or placebo $(n=110), 344(79.8 \%)$ patients remained on abatacept at year 2. Detailed patient disposition data are provided in supplementary figure 1 (available online only). Patient demographics and baseline clinical characteristics for patients who entered the LTE were consistent with those for the original randomly assigned population, ${ }^{6}$ and were comparable between original groups (supplementary table A, available online only).

\section{Concomitant medications}

During the 1-year open-label LTE, 98.5\% of all patients (both original abatacept and infliximab arms) received concomitant methotrexate. Other than methotrexate, concomitant non-biological disease-modifying antirheumatic drugs administered during the LTE included azathioprine (for original abatacept and infliximab arms, respectively; $0.8 \%$ vs $3.7 \%$ ), hydroxychloroquine/chloroquine (1.5\% vs $2.2 \%$ ), leflunomide ( $2.3 \%$ vs $3.7 \%$ ) and sulfasalazine ( $4.5 \%$ vs $4.4 \%$ ).

\section{Clinical efficacy}

The proportions of patients achieving DAS28-defined LDAS and remission, and those achieving SDAI-defined low disease activity and remission are shown in figure $1 \mathrm{~A}, \mathrm{~B}$. Rates of LDAS and remission, according to both DAS28 and SDAI, increased numerically from year 1 to year 2 in the original abatacept group; for patients originally randomly assigned to infliximab, rates increased following the switch to abatacept. ACR 50 and 70 responses, EULAR responses, reductions from baseline in DAS28 (ESR) and HAQ-DI scores are shown in the supplementary material available online only.

Table 1 Post-hoc analyses of shifts in ACR responses and DAS28 (ESR) states between year 1 and year 2, following switch from infliximab to abatacept

\begin{tabular}{|c|c|c|c|c|c|}
\hline \multicolumn{2}{|c|}{ ACR response* at year 1} & \multicolumn{3}{|c|}{ Shifts in ACR response* by year $2, n(\%)$} & \multirow[b]{2}{*}{ ACR70 } \\
\hline & Total, n (\%) & $\begin{array}{l}\text { No } \\
\text { response }\end{array}$ & $\begin{array}{l}\text { ACR20 } \\
\text { (not ACR50/70) }\end{array}$ & $\begin{array}{l}\text { ACR50 } \\
\text { (not ACR70) }\end{array}$ & \\
\hline No response & $39(30.7)$ & $10(25.6)$ & $11(28.2)$ & $13(33.3)$ & $5(12.8)$ \\
\hline $\begin{array}{l}\text { ACR } 20 \\
\text { (but not ACR50/70) }\end{array}$ & $32(25.2)$ & $7(21.9)$ & $5(15.6)$ & $9(28.1)$ & $11(34.4)$ \\
\hline $\begin{array}{l}\text { ACR } 50 \\
\text { (but not ACR70) }\end{array}$ & 24 (18.9) & $3(12.5)$ & $1(4.2)$ & $8(33.3)$ & $12(50.0)$ \\
\hline ACR 70 & $32(25.2)$ & 0 & 0 & $3(9.4)$ & $29(90.6)$ \\
\hline \multicolumn{2}{|c|}{ DAS28 (ESR) status* at year 1} & \multicolumn{4}{|c|}{ Shifts in DAS28 (ESR) status* by year $2, n(\%)$} \\
\hline & Total, $\mathbf{n}(\%)$ & $\begin{array}{l}\text { HDAS } \\
\text { (DAS28 >5.1) }\end{array}$ & $\begin{array}{l}\text { MDAS } \\
\text { (DAS28 >3.2-5.1) }\end{array}$ & $\begin{array}{l}\text { LDAS } \\
\text { (DAS28 2.6-3.2) }\end{array}$ & $\begin{array}{l}\text { Remission } \\
\text { (DAS28 <2.6) }\end{array}$ \\
\hline $\begin{array}{l}\text { HDAS } \\
\text { (DAS28 >5.1) }\end{array}$ & $39(31.2)$ & $8(20.5)$ & $25(64.1)$ & $2(5.1)$ & $4(10.3)$ \\
\hline $\begin{array}{l}\text { MDAS } \\
\text { (DAS28 >3.2-5.1) }\end{array}$ & $56(44.8)$ & $4(7.1)$ & $25(44.6)$ & $15(26.8)$ & $12(21.4)$ \\
\hline $\begin{array}{l}\text { LDAS } \\
\text { (DAS28 2.6-3.2) }\end{array}$ & $12(9.6)$ & $1(8.3)$ & $4(33.3)$ & $1(8.3)$ & $6(50.0)$ \\
\hline $\begin{array}{l}\text { Remission } \\
\text { (DAS28 <2.6) }\end{array}$ & $18(14.4)$ & 0 & $1(5.6)$ & $3(16.7)$ & 14 (77.8) \\
\hline
\end{tabular}

${ }^{*} \mathrm{ACR}$ response and DAS28 status categories are discrete.

ACR, American College of Rheumatology; DAS28, disease activity score in 28 joints; ESR, erythrocyte sedimentation rate; HDAS, high disease activity state; LDAS, low disease activity state; MDAS, moderate disease activity state. 


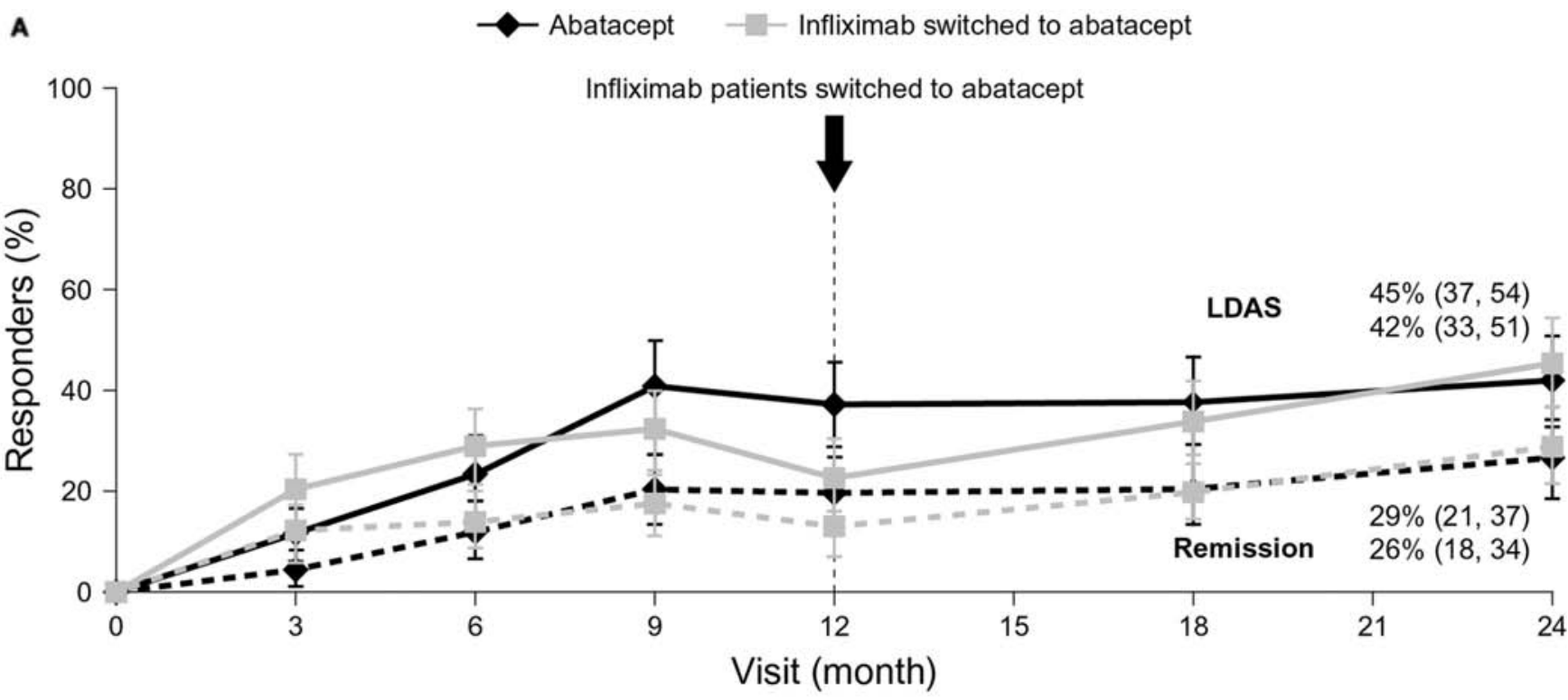

\begin{tabular}{|l|c|c|c|c|c|c|c|}
\hline \multicolumn{8}{|c|}{ Number of patients with available data at each visit } \\
\hline & Month 0 & Month 3 & Month 6 & Month 9 & Month 12 & Month 18 & Month 24 \\
\hline Abatacept & 127 & 132 & 132 & 129 & 127 & 122 & 115 \\
\hline Infliximab & 131 & 136 & 135 & 134 & 135 & 125 & 126 \\
\hline
\end{tabular}

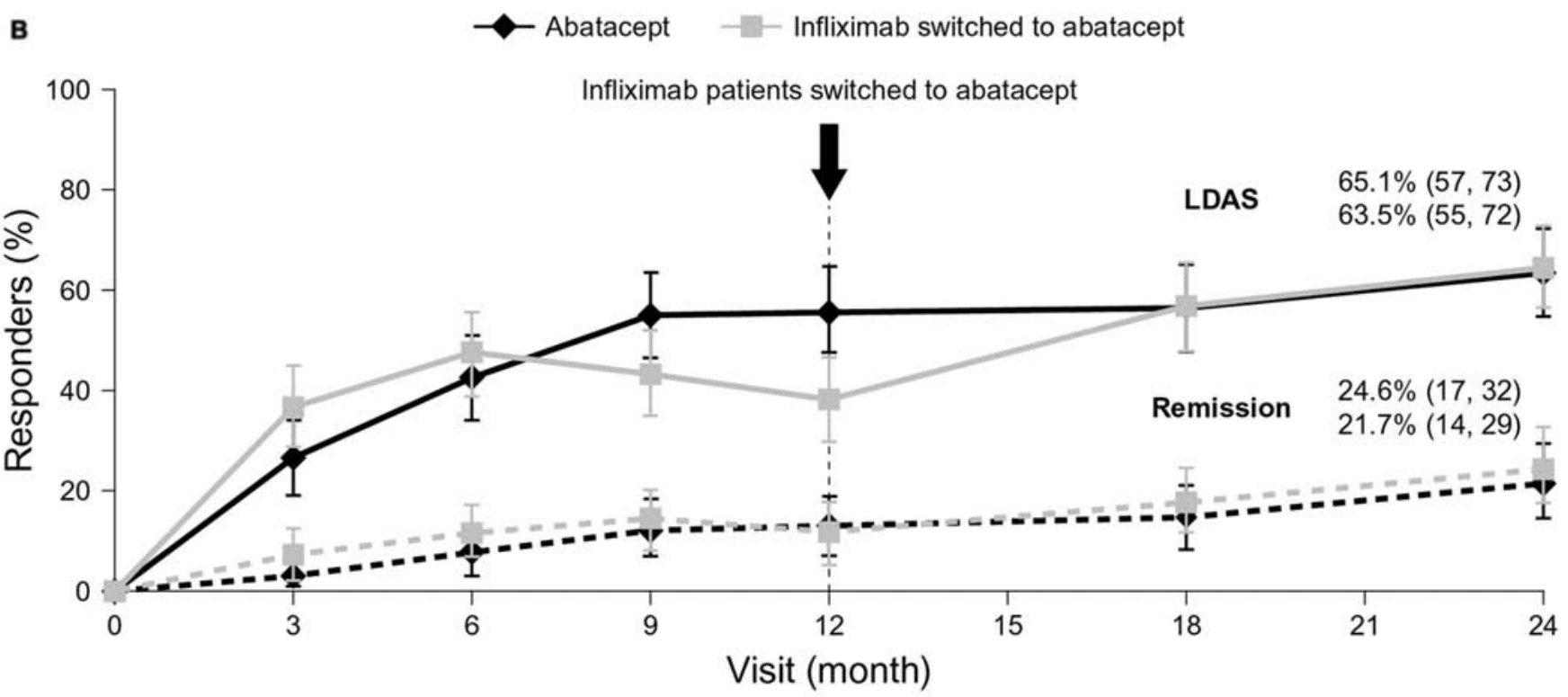

\begin{tabular}{|l|c|c|c|c|c|c|c|}
\hline \multicolumn{7}{|c|}{ Number of patients with available data at each visit } \\
\hline & Month 0 & Month 3 & Month 6 & Month 9 & Month 12 & Month 18 & Month 24 \\
\hline Abatacept & 130 & 131 & 132 & 129 & 130 & 122 & 115 \\
\hline Infliximab & 136 & 136 & 133 & 135 & 135 & 125 & 126 \\
\hline
\end{tabular}

Figure 1 Data are for patients originally assigned to abatacept or infliximab and switched to abatacept at year 1. Original placebo group is not shown. (A). Percentage (95\% Cl) of patients in DAS28 (ESR) LDAS and remission. At year 1, 37.0 (95\% Cl: 28.6 to 45.4$)$ vs $23.0 \%$ (15.9 to 30.1 ) of abatacept- versus infliximab-treated patients, respectively, achieved LDAS, and 19.7 (12.8 to 26.6) versus $13.3 \%$ (7.6 to 19.1) achieved remission. At year 2, 41.7 (95\% Cl: 32.7 to 50.8 ) versus $45.2 \%$ (36.5 to 53.9) of original abatacept versus infliximab-to-abatacept switch patients, respectively, achieved LDAS, and 26.1 (18.1 to 34.1 ) versus $28.6 \%$ (20.7 to 36.5 ) achieved remission. (B). Percentage (95\% CI) of patients in SDAI LDA and remission. At year 1, 56.2 (95\% Cl: 47.6 to 64.7 ) versus 38.5\% (30.3 to 46.7) of abatacept- vs infliximab-treated patients, respectively, achieved LDA, and 13.1 (7.3 to 18.9) versus $11.9 \%$ (6.4 to 17.3 ) achieved remission. At year 2, 63.5 (95\% Cl: 54.7 to 72.3 ) versus $65.1 \%$ (56.8 to 73.4 ) of original abatacept vs infliximab-to-abatacept switch patients, respectively, achieved LDA, and 21.7 (14.2 to 29.3 ) versus $24.6 \%$ (17.1 to 32.1 ) achieved remission. 


\section{Patient-level clinical efficacy analyses}

After 1 year of infliximab treatment, $30.7 \%$ of patients were ACR 20 non-responders, and $25.2 \%, 18.9 \%$ and $25.2 \%$ achieved ACR 20, 50 and 70 responses, respectively, with $31.2 \%, 44.8 \%$, $9.6 \%$ and $14.4 \%$ of patients in high disease activity state, moderate disease activity state (MDAS), LDAS and remission, respectively. Table 1 shows the shifts in ACR responses and DAS28 states for these patients from years 1 to 2 .

\section{Safety}

Abatacept was generally well tolerated over the cumulative 2-year study period (table 2). Osteoarthritis (five patients) was the only SAE reported in $1 \%$ or more of patients, other than worsening of rheumatoid arthritis. Two deaths were reported in the open-label period (respiratory failure and accidental).

The most common infections $(\geq 10 \%$ of patients) were nasopharyngitis, urinary tract infection, upper respiratory tract infection, influenza and pharyngitis; and for serious infections were pneumonia and urinary tract infection (three patients each). There was a single report of latent tuberculosis during the LTE in a patient originally randomly assigned to infliximab, considered severe. The patient had a negative chest x-ray and purified protein derivative (PPD) test at study entry, and a positive PPD test and chronic bronchitis and basal fibrosis on x-ray at month 6 of the LTE; the patient did not discontinue and the event resolved after approximately 1 year.

Two malignancies were reported in the LTE, including basal cell carcinoma in a patient originally randomly assigned to abatacept, which was classified as serious and possibly related to treatment.

All autoimmune events were mild or moderate in intensity; psoriasis was the most frequent event and was reported in three patients.

Acute infusional adverse events occurred in 11 patients originally randomly assigned to infliximab after they switched to abatacept. The most common events ( $\geq 1 \%$ of patients) were headache, dizziness and nausea.
The IR of adverse events did not increase during abatacept treatment in the LTE for patients treated with infliximab and switched to abatacept at year 1 (291.4 (242.0, 347.9)), compared with that for patients treated with infliximab during the doubleblind period (448.6 (380.6, 525.3); table 2). SAE and infections for original infliximab patients were reported at IR of 16.5 (10.1, $25.4)$ and $96.9(76.9,120.4)$ in the LTE versus $21.1(14.2,30.1)$ and $134.1(110.6,161.1)$ in the double-blind period; serious infections and opportunistic infections at IR of $1.5(0.2,5.6)$ and $0.0(0.0$, $0.0)$ versus $9.2(5.0,15.5)$ and $2.6(0.7,6.6)$; and acute infusional reactions at IR of $8.9(4.4,15.9)$ versus 32.3 (23.3, 43.6).

\section{DISCUSSION}

The ATTEST trial provided an opportunity to assess the efficacy of abatacept over 2 years while concurrently evaluating patients who were switched to abatacept after initial treatment with infliximab. In the original abatacept group, improvements in disease activity achieved by the end of the double-blind period were maintained with continued abatacept treatment through the LTE. For patients switched from infliximab to abatacept at year 1, clinical efficacy benefits were maintained or increased following the switch. Observed efficacy benefits are supported by good retention rates, consistent with previous abatacept experience in this population. ${ }^{11} 12$

The majority of individual patients who switched to abatacept improved or maintained their treatment response or disease activity level at year 2, regardless of the initial response to infliximab. Many patients who had not achieved a response, or were still in high/moderate disease activity after 1 year of infliximab, achieved a response or improved their disease activity state with abatacept. In addition, the majority of patients achieving ACR 70 responses or DAS28 remission with infliximab maintained this response or state when switched. These data reassure the clinician that a patient treated with infliximab, who has experienced a good clinical response, may expect to have a continued good response with consistent safety if they

Table 2 Adverse events

\begin{tabular}{|c|c|c|c|}
\hline \multirow[b]{2}{*}{ Incidence rate $(95 \% \mathrm{Cl})$} & \multicolumn{2}{|l|}{ Double-blind period } & \multirow{2}{*}{$\begin{array}{l}\text { Cumulative 2-year } \\
\text { study period }^{\dagger} \\
\text { Abatacept, } n=399\end{array}$} \\
\hline & Abatacept* $n=156$ & Infliximab*, $n=165$ & \\
\hline Mean (range) months of exposure & $11.7(2.4-13.3)$ & $11.6(1.9-13.1)$ & $17.2(1.9-26.5)$ \\
\hline Deaths & 0.7 (0.0 to 3.7$)$ & $1.3(0.2$ to 4.6$)$ & 0.7 (0.2 to 1.8$)$ \\
\hline $\mathrm{AE}$ & $326.0(274.1$ to 384.9$)$ & 448.6 (380.6 to 525.3 ) & 257.5 (231.8 to 285.3$)$ \\
\hline SAE & $11.8(6.9$ to 18.9$)$ & 21.1 (14.2 to 30.1$)$ & $15.2(12.0$ to 19.0$)$ \\
\hline Infections & 99.8 (80.4 to 122.4$)$ & 134.1 (110.6 to 161.1$)$ & 86.2 (76.2 to 97.3$)$ \\
\hline Serious infectious events & $2.0(0.4$ to 5.9$)$ & $9.2(5.0$ to 15.5$)$ & $1.6(0.7$ to 3.1$)$ \\
\hline Opportunistic infections & 0 & $2.6(0.7$ to 6.6$)$ & $0.2(0.0$ to 1.0$)$ \\
\hline Neoplasms $^{\ddagger}$ & $2.7(0.7$ to 6.9$)$ & $3.2(1.0$ to 7.5$)$ & 2.7 (1.5 to 4.5$)$ \\
\hline Malignant neoplasms & $0.7(0.0$ to 3.7$)$ & $1.3(0.2$ to 4.6$)$ & $0.4(0.0$ to 1.3$)$ \\
\hline Autoimmune symptoms or events & $1.3(0.2$ to 4.8$)$ & $0.6(0.0$ to 3.6$)$ & $1.4(0.6$ to 2.8$)$ \\
\hline Acute infusional $\mathrm{AE}$ & 7.7 (3.8 to 13.8 ) & 32.3 (23.3 to 43.6$)$ & $6.4(4.5$ to 9.0$)$ \\
\hline
\end{tabular}

* Represents original randomisation group and events experienced in the double-blind period (updated database lock relative to previously published double-blind findings). ${ }^{6}$

${ }^{t}$ Patients who received at least one infusion of abatacept in the cumulative study period (double-blind or long-term extension) regardless of original randomisation group.

‡Benign, malignant and unspecified.

Incidence rates (IR) are calculated as the number of patients with the event of interest, divided by total exposure

(patient-years) during the specified treatment period, multiplied by 100 to provide incidence/100 patient-years of exposure.

A patient's contribution to exposure ended at the time of first occurrence of the specific $A E$.

$A E$, adverse event; $S A E$, serious adverse event. 
are switched to abatacept; an important clinical consideration if patients are switched because of safety concerns.

Abatacept was generally safe and well tolerated during this study. Transitioning patients directly from infliximab to abatacept without a washout period did not result in higher overall frequencies of SAE or infections after switching medication, relative to previous double-blind infliximab treatment over 1 year; in particular, incidence rates of serious and opportunistic infections were lower after patients switched to abatacept. These data support previously published findings that demonstrated that switching directly from an anti-TNF to abatacept without a washout period was generally safe and well tolerated. ${ }^{4}$

The findings presented here should be considered within certain limitations. Efficacy data are based on as-observed analyses, which are vulnerable to dropouts; however, discontinuation rates were relatively low and, therefore, the findings probably provide an accurate representation of the randomly assigned population. It should be noted that the patient-level results reported here are post-hoc analyses, and caution should be used with such data. During the 1-year double-blind period, the infliximab dose could not be increased beyond $3 \mathrm{mg} / \mathrm{kg}$, the recommended dosing regimen at the time of trial design. In the current clinical setting, many physicians use approved higher doses, although there has been extensive debate over the efficacy benefits of such dose escalation ${ }^{13-15}$ and reports of an increased incidence of infections with higher doses. ${ }^{16}$ However, the objective of the current study was to assess safety and efficacy in patients who switch to abatacept, regardless of treatment response, and, thus, included patients responding to treatment with infliximab. Therefore, the fact that dose escalation of infliximab was not permitted in the double-blind period should not detract from these findings.

The definition of an 'inadequate response' to therapy is changing, with clinical remission a clear therapeutic goal and LDAS an acceptable alternative in patients with long-standing, established disease. ${ }^{17}$ As such, patients and clinicians now have ever higher expectations of treatment. Physicians may consider switching patients who have achieved only moderate clinical improvements, such as an ACR 20 response or MDAS. The findings presented here suggest that abatacept is a viable treatment option for such patients.

Acknowledgements The authors would like to thank Eve Guichard, Medicus International, for editorial support.

Funding This study was sponsored, and editorial support funded, by Bristol-Myers Squibb.

Competing interests MS, MD and MK have received grant support and consulting fees from Bristol-Myers Squibb. SS has received grant support from Bristol-Myers Squibb. RA, J-CB, MN, MIB and DMR are employees and stock-holders of BristolMyers Squibb. CC, AB, SN and CS have no conflict of interest to declare.

Provenance and peer review Not commissioned; externally peer reviewed.

\section{REFERENCES}

1. Genovese MC, Schiff M, Luggen M, et al. Efficacy and safety of the selective co-stimulation modulator abatacept following 2 years of treatment in patients with rheumatoid arthritis and an inadequate response to anti-tumour necrosis factor therapy. Ann Rheum Dis 2008;67:547-54.

2. Cohen SB, Emery P, Greenwald MW, et al. Rituximab for rheumatoid arthritis refractory to anti-tumor necrosis factor therapy: results of a multicenter, randomized, double-blind, placebo-controlled, phase III trial evaluating primary efficacy and safety at twenty-four weeks. Arthritis Rheum 2006:54:2793-806.

3. Emery $\mathbf{P}$, Keystone E, Tony HP, et al. IL-6 receptor inhibition with tocilizumab improves treatment outcomes in patients with rheumatoid arthritis refractory to anti-tumour necrosis factor biologicals: results from a 24-week multicentre randomised placebocontrolled trial. Ann Rheum Dis 2008;67:1516-23.

4. Schiff M, Pritchard C, Huffstutter JE, et al. The 6-month safety and efficacy of abatacept in patients with rheumatoid arthritis who underwent a washout after antitumour necrosis factor therapy or were directly switched to abatacept: the ARRIVE trial. Ann Rheum Dis 2009;68:1708-14.

5. Finckh A, Ciurea A, Brulhart L, et al. B cell depletion may be more effective than switching to an alternative anti-tumor necrosis factor agent in rheumatoid arthritis patients with inadequate response to anti-tumor necrosis factor agents. Arthritis Rheum 2007;56:1417-23

6. Schiff M, Keiserman M, Codding C, et al. Efficacy and safety of abatacept or infliximab vs placebo in ATTEST: a phase III, multi-centre, randomised, double-blind, placebo-controlled study in patients with rheumatoid arthritis and an inadequate response to methotrexate. Ann Rheum Dis 2008;67:1096-103.

7. Prevoo ML, van 't Hof MA, Kuper HH, et al. Modified disease activity scores that include twenty-eight-joint counts. Development and validation in a prospective longitudinal study of patients with rheumatoid arthritis. Arthritis Rheum 1995;38:44-8.

8. Felson DT, Anderson JJ, Boers M, et al. American College of Rheumatology Preliminary definition of improvement in rheumatoid arthritis. Arthritis Rheum 1995; 38:727-35

9. Fransen J, van Riel PL. The Disease Activity Score and the EULAR response criteria Clin Exp Rheumatol 2005;23(5 Suppl 39):S93-9.

10. Pincus T, Summey JA, Soraci SA Jr, et al. Assessment of patient satisfaction in activities of daily living using a modified Stanford Health Assessment Questionnaire. Arthritis Rheum 1983;26:1346-53.

11. Westhovens R, Kremer JM, Moreland LW, et al. Safety and efficacy of the selective costimulation modulator abatacept in patients with rheumatoid arthritis receiving background methotrexate: a 5-year extended phase IIB study. J Rheumatol 2009;36:736-42

12. Kremer JM, Genant HK, Moreland LW, et al. Results of a two-year followup study of patients with rheumatoid arthritis who received a combination of abatacept and methotrexate. Arthritis Rheum 2008;58:953-63.

13. van Vollenhoven RF, Brannemark S, Klareskog L. Dose escalation of infliximab in clinical practice: improvements seen may be explained by a regression-like effect. Ann Rheum Dis 2004;63:426-30.

14. Durez $\mathbf{P}$, Van den Bosch F, Corluy L, et al. A dose adjustment in patients with rheumatoid arthritis not optimally responding to a standard dose of infliximab of $3 \mathrm{mg} / \mathrm{kg}$ every 8 weeks can be effective: a Belgian prospective study. Rheumatology (Oxford) 2005;44:465-8.

15. Flendrie $\mathbf{M}$, Creemers MC, van Riel PL. Titration of infliximab treatment in rheumatoid arthritis patients based on response patterns. Rheumatology (Oxford) 2007;:46:146-9

16. Westhovens R, Yocum D, Han J, et al. The safety of infliximab, combined with background treatments, among patients with rheumatoid arthritis and various comorbidities: a large, randomized, placebo-controlled trial. Arthritis Rheum 2006:54:1075-86.

17. Smolen JS, Aletaha D, Bijlsma JW, et al. Treating rheumatoid arthritis to target: recommendations of an international task force. Ann Rheum Dis 2010:69:631-7. 